\title{
COnE).(OES
}

CIÊNCIA E TECNOLOGIA

PERCEPÇÕES SOBRE AS POLÍTICAS PÚBLICAS DE INCLUSÃO DIGITAL NA EDUCAÇÃO BÁSICA DURANTE A PANDEMIA DA COVID-19: UMA ANÁLISE BIBLIOGRÁFICA

\section{PERCEPÇÕES SOBRE AS POLÍTICAS PÚBLICAS DE INCLUSÃO DIGITAL NA EDUCAÇÃO BÁSICA DURANTE A PANDEMIA DA COVID-19: UMA ANÁLISE BIBLIOGRÁFICA}

\author{
Tereza Cristina Dourado Carrah Vieira Carvalho, Priscila Barros David, \\ FRANCISCO HERBERT LIMA VASCONCELOS \\ Universidade Federal do Ceará - UFC \\ <tiaterezadourado@gmail.com>.<priscila@virtual.ufc.br>.<herbert@virtual.ufc.br> \\ DOI: 10.21439/conexoes.v15i0.2097
}

\begin{abstract}
Resumo. Este estudo tem como objetivo geral desvelar concepções evidenciadas por autores acerca das políticas públicas de inclusão digital na Educação Básica, considerando as intervenções já desenvolvidas e o atual contexto sobre a utilização das TICs no ensino remoto determinado pela pandemia do novo Coronavírus. Apresenta os seguintes objetivos específicos: sinalizar as limitações sobre o uso das tecnologias no ensino remoto em diferentes situações; revelar as possibilidades para o emprego dessas ferramentas que vão ao encontro das exigências impostas pela situação atual e relacionar informações afirmadas por autores que contextualizam o ProInfo, o Programa Educação de Inovação Conectada, o uso das TICs, o Ensino Remoto, a pandemia e as diferenças educacionais. A metodologia empregada utiliza-se de uma pesquisa exploratória com abordagem qualitativa, a qual traz um embasamento por meio de levantamento bibliográfico à luz de autores como Oliveira et al. (2020), Alves e Mamede (2020), Silva e Sousa (2020), dentre outros. A busca pelos estudos se deu recorrendo à sequência de caracteres denominada string: (proinfo OR "Programa de Inovação Educação Conectada") AND pandemia, na plataforma de pesquisa Google Scholar, no período de janeiro de 2020 a março de 2021. Dessa forma, quatorze estudos apontaram a precisão de ressignificar as políticas digitais de inclusão implementadas até o momento, considerando que, no contexto atual, as ações voltadas ao emprego das ferramentas tecnológicas ainda são insuficientes para um ensino inclusivo e universal.
\end{abstract}

Palavras-chaves: Distanciamento Social. Internet. Recursos Digitais. Descontinuidade.

\section{PERCEPTIONS ABOUT PUBLIC POLICIES FOR DIGITAL INCLUSION IN BASIC EDUCATION IN THE CONTEXT OF THE PANDEMIC OF COVID-19: A BIBLIOGRAPHIC ANALYSIS}

\begin{abstract}
The general objective of this study is to unveil conceptions evidenced by authors about public policies for digital inclusion in Basic Education, considering the interventions already developed and the current context about the use of ICTs in remote education determined by the new Coronavirus pandemic. It has the following specific objectives: to signal the limitations on the use of technologies in remote education in different situations; reveal the possibilities for the use of these tools that meet the requirements imposed by the current situation and relate information stated by authors who contextualize ProInfo, the Connected Innovation Education Program, the use of ICTs, Remote Learning, the pandemic and the differences educational. The methodology used uses an exploratory research with a qualitative approach, which provides a foundation through a bibliographic survey in the light of authors such as Oliveira et al. (2020), Alves e Mamede (2020), Silva e Sousa (2020), among others. The search for the studies was carried out using the string of characters called string: (proinfo OR "Connected Education Innovation Program") AND pandemic, on the Google Scholar research platform, from January 2020 to March 2021. Thus, fourteen studies have pointed out the need to reframe the digital inclusion policies implemented so far, considering that, in the current context, actions aimed at the use of technological tools are still insufficient for inclusive and universal education.
\end{abstract}

Keywords: Social Distancing. Internet. Digital Resources. Discontinuity. 


\section{INTRODUÇÃO}

As políticas públicas na área da Educação regulam as maneiras pelas quais os indivíduos ou grupos têm acesso aos recursos, poderes ou direitos emanados do Estado que são direcionados aos componentes da sociedade. Nessa perspectiva, o termo Política Educacional é definido por Santos (2012) como toda e qualquer política desdobrada que tem a intenção de intervir nos processos formativos e informativos desenvolvidos em sociedade.

No que compete à inclusão digital na Educação Básica, uma das intervenções estabelecidas foi a fundação do Programa Nacional de Informática na Educação (PROINFO), mediante Portaria no 522/MEC, de 9 de abril de 1997, originada pelo Ministério da Educação e Cultura (MEC), no uso de suas garantias legais e sob a supervisão da Secretaria de Educação a Distância (SEED), com anuência das gestões estaduais e municipais e do Distrito Federal (BRASIL, 1997). O ProInfo é uma política educacional resultante do acúmulo de diferentes iniciativas e foi criado com o propósito inicial de promover a admissão das tecnologias na rede pública escolar por intermédio de equipamentos, como computadores, adequados para atender os alunos (PRATA, 2005).

Outra política educacional relacionada com a inserção digital e que surgiu posteriormente foi o Programa de Inovação Educação Conectada, tendo sido instituído pelo Decreto n ${ }^{\circ}$ 9.204, de 23 de novembro de 2017 (BRASIL, 2017a).

Todavia, a morosidade e a descontinuidade dessas políticas públicas são entraves que promovem o subdesenvolvimento em diversos segmentos da Educação, inclusive quanto ao conhecimento das Tecnologias da Informação e Comunicação (TICs), haja vista que a maior parte dos docentes não domina essas ferramentas e os discentes não detêm o acesso. A respeito disso, Bezerra, Veloso e Ribeiro (2021) confirmam que a lentidão e instabilidade das políticas públicas fomentam o atraso em diversos setores, sobretudo na Educação, uma vez que muitos projetos ainda não concretizados já sofreram modificações.

Outrossim, tais obstáculos foram agravados diante do contexto atual, em virtude da pandemia da Covid 19, doença causada pelo novo Coronavírus (Sars-Cov2), ocasionando a urgência do distanciamento social e do fechamento de estabelecimentos diversos, como escolas, sendo necessário o ensino remoto para continuidade do segmento de ensino-aprendizagem. De fato, medidas e orientações foram adotadas pelo Poder Executivo e acometeram todas as áreas do ensino, para as quais o MEC determinou por meio da Portaria $n^{\circ} 544$, de 16 de junho de 2020, a efetivação de práticas pedagógicas virtuais enquanto durar a emergência, e deixou a sistematização do processo a critério das escolas, faculdades e outras organizações, de modo a respeitar as especificidades das legislações regionais (BRASIL, 2020).

Com efeito, esse cenário concebeu enorme metamorfose no trabalho docente e na Educação de modo geral, provocando mudanças circunstanciais e exigindo espaço para reflexões acerca de sua organização, do papel do professor e dos alunos, da aplicação das tecnologias, bem como surgiram algumas indagações, dentre elas: será que as políticas digitais existentes suprem as demandas atuais para um ensino democrático? Justificando, assim, a relevância deste objeto de pesquisa.

Sob esse viés, busca-se responder ao seguinte questionamento: O que os estudos, à luz dos autores, apontam sobre as políticas públicas de inclusão digital na Educação Básica, considerando as ações já desenvolvidas e o atual cenário educacional imposto pela pandemia da Covid-19?

Diante do referido contexto, pressupõe-se a premência de uma ressignificação das políticas vigentes de inclusão digital, tendo em vista que a maior parte de seus programas possui ações voltadas para o cenário interno da escola. Contudo, com a brevidade da adesão do ensino remoto pelas escolas, cujas intervenções acontecem em domicílios dos alunos, pais e professores, as barreiras do desempenho das tecnologias em diferentes circunstâncias não têm possibilitado o acesso universal à Educação.

Portanto, o objetivo geral do presente estudo visa desvelar concepções evidenciadas por autores sobre as políticas públicas de inclusão digital na Educação Básica, considerando as intervenções já desenvolvidas e o atual contexto sobre a utilização das TICs no ensino remoto determinado pela pandemia do novo Coronavírus. Os objetivos específicos buscam sinalizar as limitações sobre o uso das tecnologias no ensino remoto em diferentes contextos; revelar as possibilidades para o emprego dessas ferramentas que vão ao encontro das exigências impostas pela situação atual e relacionar informações afirmadas por autores em seus estudos, contextualizando o ProInfo, o Programa Educação de Inovação Conectada, o uso das TICs, o Ensino Remoto, a pandemia e as diferenças educacionais.

Em suma, além da introdução, que apresenta a motivação, a questão e os propósitos, o trabalho está dividido em mais cinco seções. A seção 2 contextualiza exemplos de políticas de inclusão digital na Educação Básica, como o ProInfo e o Programa de Inovação Educação Conectada. Na seção 3, são apresentados os as- 
pectos metodológicos empregados na análise dos dados do estudo. Na seção 4, consideram-se os resultados obtidos e a discussão deles. Por último, na seção 5, são discorridas as considerações finais.

\section{POLÍTICAS DE INCLUSÃO DIGITAL NA EDUCAÇÃO BÁSICA}

\subsection{O Prolnfo e o Prolnfo Integrado}

As atividades do ProInfo podem ser percebidas em duas fases: a primeira, desde a sua criação em 1997 até o ano de 2006; a segunda, a partir da criação do ProInfo Integrado em 2007. Inicialmente, com a necessidade de levar inovações tecnológicas para as escolas públicas municipais do país, o governo criou o Programa Nacional de Informática na Educação (ProInfo) com base na Portaria $\mathrm{n}^{\circ}$ 522, de 9 de abril de 1997, representando uma alternativa que possibilitasse às escolas obterem novas ferramentas para estimular a pesquisa e a edificação de novos conhecimentos (BRASIL, 1997).

Na primeira fase, a execução do ProInfo aconteceu no formato descentralizado e composto de Núcleos de Tecnologia Educacional de estados e municípios (NTE e NTM). Estes centros possuíam uma infraestrutura tecnológica moderna, de modo que cada um dos estados, municípios e Distrito Federal que fizesse a adesão ao programa, possuiria sua própria coordenação, cujo objetivo era ceder suportes técnico e pedagógico ao processo de informatização nas escolas. Conforme Costa (2015), apoiado nas informações disponibilizadas pelo site oficial do MEC, o programa ProInfo destina recursos digitais às escolas, como computadores e conteúdos educacionais. Os estados, Distrito Federal e municípios se responsabilizam pela estrutura adequada para receber os equipamentos e laboratórios e pela capacitação dos educadores para o exercício e manuseio de aparatos tecnológicos.

Mais tarde, após o Decreto $\mathrm{n}^{\circ} 6.300$, de 12 de dezembro de 2007, disposto na Lei ${ }^{\circ} 10.172 / 01$, passou a ser denominado Programa Nacional de Tecnologia Educacional (ProInfo), tanto em nível urbano quanto rural. Foi iniciado pelo MEC com o objetivo de promover o uso pedagógico das tecnologias na rede pública de Educação Básica (BRASIL, 2007b). Na segunda fase, o programa foi reformulado, o qual obteve, além da mudança de nome e de ter sido proporcionado o alargamento da abrangência de cobertura, conseguiu a integração dos três eixos: a implantação de laboratórios de informática nas escolas públicas, a formação dos profissionais e a publicação de conteúdos digitais educacionais.

Com a nova formatação do programa, segundo Da- masceno, Bonilla e Passos (2012), há uma perspectiva de centralização das ações de formação, de seus conteúdos e das diretrizes. Nesse viés, os NTE e NTM passariam apenas a dar suporte aos cursos promovidos pelo programa. Ademais, a capacitação de docentes passa a ser parte do ProInfo Integrado a partir do Programa Nacional de Formação Continuada em Tecnologia Educacional e conta com a oferta dos seguintes cursos: Introdução à Educação Digital (60h); Tecnologia na Educação (60h); Elaboração de Projetos (40h) e Redes de Aprendizagem (40h), incluindo o Programa Mídias na Educação realizado na modalidade a distância (BRASIL, 2007).

Outras ações complementaram o programa, dentre elas: o Projeto Um Computador por Aluno (UCA); a criação de dispositivos tecnológicos, como exemplo o projetor interativo; o Programa Banda Larga (PNBL) nas escolas e a distribuições de tablets para professores de escolas de ensino médio. O projeto UCA foi implantado nas escolas públicas a partir da distribuição de laptops educacionais aos alunos da rede pública de ensino. Castro Filho, Silva e Maia (2015) ressaltam que esta ação produziu um legado significativo à Educação Pública para além de uma política educacional de informática ao apontarem impasses e alternativas de aprendizagens tecnológicas móveis na escola.

Vários conteúdos educacionais também foram elaborados e viabilizados pelo ProInfo Integrado, e estes, por sua vez, foram inseridos em rede e mantidos pela União e disponibilizados pelo site do MEC, oferecendo recursos disponíveis para os vários níveis de ensino, tais como: o Portal do Professor; a TV Escola; o DVD Escola; o Portal Domínio Público e o Banco Internacional de Objetos Educacionais. Consoante, Valente e Almeida (2020) afirmam que o Portal do Professor é um espaço virtual que dispõe de vários recursos educacionais digitais, cursos, notícias, materiais de estudo, banco de sugestões de aulas, links para outros portais e para o ambiente colaborativo de aprendizagem e-ProInfo, este mantido pelo MEC.

As universidades tiveram um papel significativo em várias ações do ProInfo, assegurando a implementação de pesquisas que subsidiaram as políticas públicas, a produção de conhecimento sobre as inovações tecnológicas na educação e a formação de profissionais. Nesse âmbito, Prata (2005) ressalta que o governo formou uma representação composta por professores de diversas universidades e consultores na área de informática, bem como criou sistemas para conduzir a formação de professores e a supervisão das ações no país.

Pode-se considerar que o ProInfo trouxe grandes contribuições no processo de inclusão digital, sendo o 
programa de informática das escolas públicas mais importante até o momento, todavia, Damasceno, Bonilla e Passos (2012), apesar de confirmarem sua relevância nas últimas décadas, enfatizam que a inserção das TICs na Educação com a instalação dos laboratórios de informática nas escolas também vem, de forma geral, sem um aprofundamento sobre os novos hábitos sociais gerados por esses conhecimentos.

\subsection{Programa de Inovação Educação Conectada}

A partir de novembro de 2017, O MEC implementou o Programa de Inovação Educação Conectada pelo Decreto $n^{\circ} 9.204$ como uma política que aplica tecnologia para globalização do acesso à internet em alta velocidade e estimula o emprego educativo dessas inovações digitais na Educação Básica (BRASIL, 2017b).

Segundo Silva e Casagrande (2020), o programa foi elaborado a partir de quatro dimensões: visão, formação, recursos educacionais digitais e infraestrutura. Elas se complementam e devem estar em concordância a fim de que a operação de ferramentas tecnológicas digitais tenha efeito construtivo na Educação e proporcione a redução das desigualdades sociais. Assim, o programa encontra-se articulado com a meta 7 do Plano Nacional de Educação (PNE) conforme Lei no 13.005, de 25 de junho de 2014, que determinou o estímulo da elaboração, inserção, afirmação e difusão das tecnologias no ensino (BRASIL, 2014).

Sua implementação, definida no artigo $2^{\circ}$ da Portaria $n^{\circ} 1602 / 2017$, será feita por fases compreendidas entre o intervalo dos anos 2017 a 2024, constituindose como um esforço conjunto entre órgãos e entidades da União, dos estados, do Distrito Federal, dos municípios, escolas, setor empresarial e sociedade civil (BRASIL, 2017a). As fases do programa, instituídas pelo governo, possuem metas com ampliação do serviço e contemplam gradualmente escolas urbanas e rurais, como também a velocidade da internet a ser disponibilizada. Elas estão definidas como: Indução, Expansão e Sustentabilidade.

A primeira fase, a Indução, compreende o período de 2017 a 1018 e propõe a concepção e implantação do programa. A fase Expansão abrange o intervalo de 2019 a 2021 e tem como meta ampliar a assistência aos alunos da Educação Básica e verificar a qualidade da conectividade. A eficiência dessa conexão será avaliada com auxílio de um aplicativo de monitoramento, do aproveitamento dos recursos digitais e da capacidade de gestão dos meios financeiros. Ademais, a terceira fase, definida como Sustentabilidade, compreende o espaço de 2022 a 2024 e estabelece como meta o suporte para todos os alunos (BRASIL, 2017a).
Sob esse viés, o projeto se encontrava em fase de expansão e com o surgimento da pandemia, mais uma vez as barreiras da inclusão digital na Educação ficaram perceptíveis. Contudo, conforme (SILVA; CASAGRANDE, 2020), já se observam projetos de leis que visam tornar o Programa Educação Conectada como política de Estado, visando evitar sua descontinuidade ou mesmo a diminuição de suas ações por decisão política do Poder Executivo.

\section{METODOLOGIA}

Este artigo apresenta a seguinte questão de pesquisa: $\mathrm{O}$ que os estudos, à luz de autores, apontam sobre as políticas públicas de inclusão digital na Educação Básica, considerando as ações já desenvolvidas e o atual cenário educacional imposto pela pandemia da Covid19 ?

$\mathrm{Na}$ perspectiva de respondê-la, este artigo utiliza a pesquisa exploratória com abordagem qualitativa, tendo embasamento por meio de um levantamento bibliográfico que, consoante as palavras de Lima e Mioto (2007), implica em um sistema ordenado de procedimentos de busca de soluções atento ao objeto de estudo, ou seja, necessita de critérios claros e bem definidos que são continuamente avaliados e ressignificados à medida que constroem a busca por explicações.

A sistematização e as análises obedecem às seguintes etapas: definição do banco de dados e string de busca, seleção e organização dos trabalhos a serem analisados e coleta dos elementos que podem elucidar o atual problema de pesquisa. Dessa forma, atribuindo caracterização à literatura nacional, a busca pelos estudos ocorreu por meio de string: (Proinfo OR "Programa de Inovação Educação Conectada") $A N D$ pandemia, na plataforma de pesquisa Google Scholar, no período de janeiro de 2020 a março de 2021, onde foram encontrados 158 trabalhos.

Assim, para a escolha dos trabalhos, foram utilizados critérios de inclusão que obedeceram ao problema da pesquisa e ao ano de publicação voltados para o contexto da pandemia da Covid 19 na Educação Básica e para as Políticas de Inclusão Digital, servindo como base para a construção deste trabalho. Após a leitura dos títulos, resumos e palavras-chave foram selecionados 14 artigos científicos de periódicos. Os dados foram extraídos e organizados por meio do software Zotero, o que possibilitou o agrupamento e sistematização dos resultados de busca obtidos em uma matriz de síntese, ou seja, uma planilha contendo o nome da base de dados, o título do artigo, o nome do autor ou autores, o título do periódico, o ano de publicação, o endereço eletrônico e as respostas dos objetivos e questão. 

COVID-19: UMA ANÁLISE BIBLIOGRÁFICA

Com a identificação dos trabalhos, procedeu-se à análise dos dados a partir da leitura dos artigos. Em conformidade com Lima e Mioto (2007), a leitura se apresenta como principal técnica, já que é por intermédio dela que se torna possível detectar as informações e os dados contidos nos estudos selecionados, bem como verificar as relações entre eles de modo a analisar a sua consistência. Por fim, realizou-se a síntese integradora como resultante da análise e reflexão dos documentos.

\section{RESULTADOS E DISCUSSÕES}

Este estudo está relacionado a outros trabalhos, como Oliveira et al. (2020), Alves e Mamede (2020), Silva e Sousa (2020), dentre outros, que tiveram o intuito de mostrar a relevância do uso das tecnologias no contexto da pandemia. Entretanto, o presente artigo se diferencia por identificar as barreiras e alternativas da aplicação das TICs no ensino remoto, que são aspectos importantes para revelar a precisão da criação e efetividade de políticas educacionais. Além disso, apontar uma sequência de ideias, pensamentos, entendimentos, noções e discernimentos sobre as políticas educacionais de inclusão digital, contextualizando os projetos existentes e o cenário atual. Por conseguinte, conduzir para uma reflexão acerca da criação de políticas de inclusão digital que possam levar tecnologias para além dos muros da escola de forma democrática, conforme serão detalhados a seguir.

\subsection{Limitações acerca do Uso das TICs no Ensino Remoto direcionadas aos professores, alunos, pais e instituições}

O isolamento social provocado pela Covid-19 abalou radicalmente o processo de ensino e a aprendizagem na Educação Básica em detrimento da escassez de acesso à internet e às aulas on-line Pereira (2020). Outrossim, é importante relatar que o ensino remoto proporcionou o acúmulo de responsabilidades dentro dos lares e, neste sentido, tem forçado os pais e responsáveis a dividirem sua atenção entre seus afazeres domésticos e a educação dos seus filhos.

Segundo a Constituição Federal de 1988, no artigo 205, é encargo do Estado e da família beneficiar a todos com a educação, proporcionando a justiça de oportunidades para o ingresso e subsistência na escola (BRASIL, 1988). Nessa perspectiva, a equidade de condições de uma educação para todos ocorre a partir de políticas públicas efetivas de democratização, com acesso ao ensino, seja presencial ou remoto e tem gerado considerações significativas.
No que tange aos docentes, o rompimento das aulas presenciais demandou adaptação das suas atividades profissionais, tornando suas casas em novo local de trabalho, com uma nova rotina e inúmeros desafios a serem enfrentados. De acordo com Oliveira et al. (2020), os educadores estão expostos a um trabalho docente precário e com um expediente de ocupação que supera as 40 horas semanais, custeando dispositivos, buscando conhecimento por conta própria e assumindo o papel do Estado. De fato, os docentes têm vivenciado situações adversas nessa nova maneira de ensinar e, segundo Alves e Mamede (2020), muitos declaram estar exaustos e têm apresentado reclamações generalizadas, exemplificadas pela sobrecarga devido aos atendimentos que se estendem ao longo do dia e adentram o turno da noite.

Outro ponto a ser considerado é que, no Brasil, as desigualdades entre o sistema privado e público, urbano e rural de ensino são notórias. Nesse âmbito, Pereira (2020) afirma que as ferramentas digitais no campo educacional estão presentes em algumas escolas e em outras não, apesar das inúmeras iniciativas de inclusão das TDICs na Educação. Sobre essa realidade da Educação brasileira, a Organização das Nações Unidas para a Educação, a Ciência e a Cultura (UNESCO) reivindica aos governantes, com urgência, a providência de proporcionarem a inclusão digital de todos os estudantes da rede pública de ensino, tendo o intuito de suprimir a exclusão tecnológica e a desigualdade educacional (UNESCO, 2020).

Nas concepções destacadas por Silva e Sousa (2020), gerou-se o seguinte questionamento: como dialogar sobre educação universal se existem estudantes sem acesso à internet e a recursos digitais de aprendizagem continuada? Diante da reflexão, seguem na Tabela 1 as principais limitações evidenciadas nos estudos sobre o uso das TICs no ensino remoto que causam desvantagens aos alunos, professores, pais e instituições.

Percebe-se claramente que muitas dessas barreiras apresentadas podem acarretar sérias consequências para a Educação. Segundo Pereira (2020), a falta de estímulo dos estudantes acaba por desencadear elevados índices de repetência e evasão escolar, ou seja, o fracasso do processo de ensino-aprendizagem.

Corrobora-se a partir de tais estudos que no contexto atual e diante da pandemia do coronavírus, a aplicação dos recursos tecnológicos no ensino remoto apresentou diversas barreiras. Nesse âmbito, eles apontaram a necessidade de ressignificar as políticas educacionais de inclusão digital da Educação Básica, conforme discorrem os autores Silva e Sousa (2020, p. 9):

\footnotetext{
“...frente aos entraves, a pandemia é um alerta para a criação, ampliação e consolidação das políticas de inclusão
} 
PERCEPÇÕES SOBRE AS POLÍTICAS PÚBLICAS DE INCLUSÃO DIGITAL NA EDUCAÇÃO BÁSICA DURANTE A PANDEMIA DA COVID-19: UMA ANÁLISE BIBLIOGRÁFICA

Tabela 1: Limitações de uso das TICs no Ensino Remoto

\begin{tabular}{|l|l|l|l|}
\hline Professores & Alunos & Pais ou responsáveis & Instituições \\
\hline $\begin{array}{l}\text { Escassez de recursos, tais como: } \\
\text { chip, celular, notebook ou } \\
\text { internet; sem os suportes das } \\
\text { políticas educacionais }\end{array}$ & $\begin{array}{l}\text { Escassez de recursos, tais como: } \\
\text { chip, celular, notebook ou } \\
\text { internet, sem os suportes das } \\
\text { políticas educacionais }\end{array}$ & $\begin{array}{l}\text { Não dispõem de condições } \\
\text { financeiras para adquirir } \\
\text { tais recursos tecnológicos }\end{array}$ & Desigualdades regionais \\
\hline $\begin{array}{l}\text { Inexperiência com os recursos } \\
\text { digitais }\end{array}$ & $\begin{array}{l}\text { Dificuldades de acesso aos } \\
\text { aplicativos oferecidos pelas } \\
\text { escolas }\end{array}$ & $\begin{array}{l}\text { Boa parte dos domicílios } \\
\text { não possuem acesso à } \\
\text { internet }\end{array}$ & $\begin{array}{l}\text { Maior adesão das } \\
\text { tecnologias nas } \\
\text { escolas estaduais }\end{array}$ \\
\hline $\begin{array}{l}\text { Condiç̃̃es precarizadas de } \\
\text { trabalho }\end{array}$ & $\begin{array}{l}\text { O retorno insatisfatório das } \\
\text { atividades e as avaliações não } \\
\text { mostram o real aprendizado }\end{array}$ & $\begin{array}{l}\text { Memória insuficiente } \\
\text { em seus celulares }\end{array}$ & $\begin{array}{l}\text { Escassez de energia } \\
\text { elétrica em algumas } \\
\text { regiões }\end{array}$ \\
\hline $\begin{array}{l}\text { Lugar inadequado para } \\
\text { manuseio das tecnologias, } \\
\text { gerando complicações à saúde }\end{array}$ & $\begin{array}{l}\text { Nem todos os alunos recebem } \\
\text { a atenção dos professores nos } \\
\text { encontros virtuais }\end{array}$ & $\begin{array}{l}\text { Falta de conhecimento para } \\
\text { mediar as atividades dos } \\
\text { filhos }\end{array}$ & $\begin{array}{l}\text { Dificuldades de } \\
\text { implantação de } \\
\text { programas em áreas de } \\
\text { difícil acesso }\end{array}$ \\
\hline $\begin{array}{l}\text { Improvisação de espaços para } \\
\text { gravação de videoaulas }\end{array}$ & $\begin{array}{l}\text { Resistência ao ensino remoto } \\
\text { devido à pouca familiaridade } \\
\text { com as tecnologias }\end{array}$ & $\begin{array}{l}\text { Os pais só disponibilizam } \\
\text { seus celulares aos filhos à } \\
\text { noite, pois muitos } \\
\text { trabalham }\end{array}$ & $\begin{array}{l}\text { Infraestrutura } \\
\text { tecnológica } \\
\text { inadequada }\end{array}$ \\
\hline Internet de má qualidade & Internet de má qualidade & Internet de má qualidade & $\begin{array}{l}\text { Internet de má } \\
\text { qualidade }\end{array}$ \\
\hline $\begin{array}{l}\text { Capacitação deficiente na } \\
\text { inclusão das TICs }\end{array}$ & $\begin{array}{l}\text { Exclusão das pessoas que } \\
\text { apresentam quaisquer tipos } \\
\text { de deficiência }\end{array}$ & $\begin{array}{l}\text { Falta de familiaridade com } \\
\text { as tecnologias }\end{array}$ & $\begin{array}{l}\text { Acecursos, } \\
\text { principalmente em aos } \\
\text { zonas rurais }\end{array}$ \\
\hline
\end{tabular}

digital no cotidiano escolar; a valorização do aprendizado através de mídias; a aplicação de softwares educativos; o auxílio na aquisição de notebooks, computadores; a disponibilização de pendrives; o auxílio para contratação de pacote de dados, serviços de internet; a implementação de serviços de teleconferência; a criação de telecentros e de Centros Vocacionais Tecnológicos; a oferta de oficinas, treinamentos e cursos de qualificação e aperfeiçoamento para otimização do uso dos recursos tecnológicos etc."

Diante da reflexão dos autores, torna-se relevante considerar que várias ações do governo foram realizadas para inclusão das inovações tecnológicas na Educação, conforme citadas pelos programas ProInfo e o mais atual, que é o Inovação Educação Conectada. Não obstante as limitações acima apresentadas, ficou ainda mais evidente que no contexto da pandemia, essas políticas não foram consolidadas abarcando toda a sociedade.

\subsection{Possibilidades de Uso das TICs no Ensino Re- moto}

As TICs têm se apresentado como ferramentas úteis e proveitosas para a evolução da sociedade, e o setor educacional vem, aos poucos, absorvendo esses novos conhecimentos. Em conformidade com os estudos de Mariano e Silva (2020), as novas tecnologias da informação e comunicação destravam novas alternativas e abrangem novos estímulos para o ofício docente.
Ademais, essas são ferramentas didáticas e pedagógicas que, caso utilizadas de forma eficiente e consciente, têm beneficiado o processo de aprendizagem interativa e possibilitado ao professor o crescimento crítico, criativo e reflexivo. De acordo com Pereira (2020), o desempenho da internet móvel por meio de smartphones oportuniza o acesso às redes sociais e aos aplicativos atrativos, disputando cada vez mais a atenção dos discentes.

De acordo com os estudos analisados, o uso das TICs no ensino remoto possibilita aos professores: a modernização das práticas antigas, a aceleração da informação e comunicação dos conhecimentos científicos do currículo prescrito, o aumento da qualidade do planejamento pedagógico, a ampliação de estratégias de ensino para facilitar a compreensão dos alunos sobre os conteúdos de ensino, além de potencializar, promover e favorecer a absorção do conteúdo e a participação dos estudantes.

No contexto da pandemia, vários caminhos foram apresentados e utilizados pelo professor para realização e aplicação de suas aulas, orientando e possibilitando a elaboração do conhecimento dos seus alunos. A respeito disso, Mariano e Silva (2020) afirma que nesse momento o educador é capaz de guiar os estudantes para a prática assertiva das ferramentas tecnológicas, implementando um ensino mais atraente, inovador 
e para além dos muros da escola. De fato, os docentes precisaram criar estratégias para o ensino remoto e hoje podem contar com várias ferramentas, dentre elas: os Ambientes Virtuais de Aprendizagens (AVAs), as Salas Virtuais, as Redes Sociais e outros recursos que possibilitam o aprendizado dos alunos por intermédio de tecnologias. Segundo Dias et al. (2020), os AVAs representam softwares habilitados para armazenar informações e conteúdos variados apresentados em formato de cursos de formação. Na Figura 1 é mostrado alguns dos recursos citados pelos autores que estão sendo utilizados pelos professores no ensino remoto.

Figura 1: Possibilidades sobre Uso das TICs no Ensino Remoto Recursos.

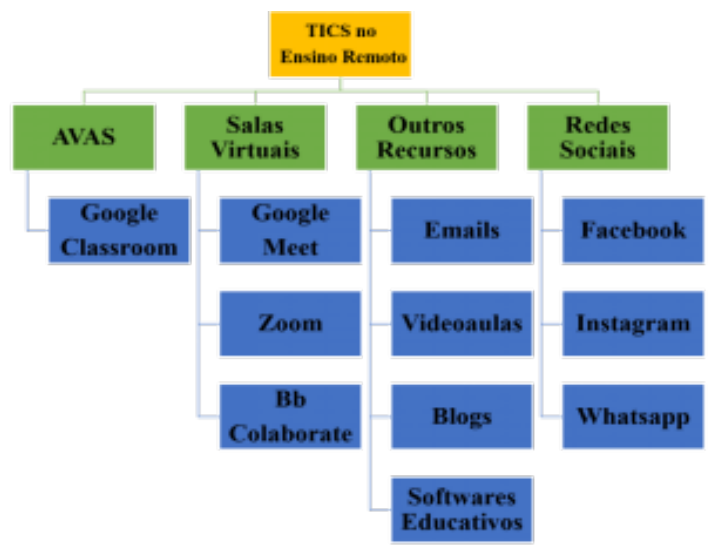

Além disso, é importante ressaltar neste estudo que a Base Nacional Comum Curricular (BNCC) abrange o crescimento de capacidades relacionadas com o exercício crítico e responsável das inovações digitais (BRASIL, 2018). Sob esse viés, à luz dos autores, destacamse as possibilidades de uso das TICs no ensino remoto, contemplando várias habilidades que podem ser desenvolvidas pelos alunos, tais como: interação, comunicação, rapidez, colaboração, desenvoltura e inclusão.

É destacável que um dos objetos de estudo ressaltou a Educação Escolar Indígena como uma das modalidades de ensino que também necessita de ampla inclusão de política pública tecnológica das TICs. Para Pereira (2020), a efetivação da política tecnológica da manipulação das TDICs nos planejamentos atuais para o ensino e aprendizado proporciona a difusão entre as etnias, compartilhando, então, lutas e reivindicações. Ademais, os estudos apontaram que as tecnologias na educação corroboram a promoção de maior conectividade entre os povos indígenas, socializam práticas educativas exitosas, promovem debates acerca de pontos comuns na agenda nacional para a modalidade de ensino, melhoram a prática pedagógica, proporcionam a socialização digital de práticas educativas exitosas das escolas indígenas distribuídas no território brasileiro, favorecem rapidez de informação e comunicação entre as etnias concernentes a assuntos de interesses comum e ainda viabilizam maior agilidade de conhecimento e diálogo com as secretarias de educação, visto que as escolas indígenas encontram-se localizadas distantes do meio urbano.

Por fim, é válido salientar as alternativas da execução das inovações tecnológicas no ensino remoto para os alunos com deficiência. De acordo com a Lei $n^{\circ}$ 9394/96 de Diretrizes e Bases da Educação Nacional (LDB), é responsabilidade do Estado viabilizar gratuitamente a acessibilidade dos estudantes com necessidades específicas no atendimento educacional especializado, de preferência no ensino regular (BRASIL, 1996).

Baseado nessa perspectiva, as facilidades apresentadas para contemplar e facilitar o aprendizado dos estudantes deficientes por meio das tecnologias foram: emprego da linguagem de sinais e legendas, ampliação de dispositivos de mídias com material didático em vídeo com tradução em libras, emprego de leitores de tela, sintetizadoras de voz, letra ampliada, material didático transcrito em braile, softwares para acessibilidades e websites com tecnologias específicas que viabilizam a superação das dificuldades de aprendizagem, como ponteiras de cabeça, teclados alternativos, acionadores, entre outros.

\subsection{Associação de informações afirmadas por au- tores sobre as Políticas de Inclusão Digital contextualizando o Prolnfo, o Programa Edu- cação de Inovação Conectada, o uso das TICs, o Ensino Remoto, a Pandemia e as diferenças educacionais}

Percebe-se a partir deste estudo a existência de projetos de informatização nas escolas com o intuito de possibilitar a prática das TICs no processo de ensino e aprendizagem. Todavia, constatou-se até a presente data que o avanço dessa democratização tecnológica nas escolas não se concretizou absolutamente em algumas regiões. Sobre isso, Mariano e Silva (2020) confirma que não é de hoje a presença de programas de inclusão digital, porém, a oferta de uma educação mediada por essas ferramentas inovadoras sempre enfrentou entraves, principalmente no que diz respeito à desinformação, à escassez de acesso e, sobretudo à insuficiência de preparo dos docentes.

Em seus estudos, o autor ainda enfatiza que os laboratórios de informática de algumas escolas nunca foram montados e certos computadores nunca saíram das caixas; esse descompromisso surtiu efeito a longo prazo, 
percebido pelo fato de que uma parcela considerável de professores se acomodou com o descuido dos governantes no que tange à fiscalização do programa. Referente a esse viés, Bezerra, Veloso e Ribeiro (2021) consideram que apenas com uma breve vistoria em qualquer escola pública, principalmente nas séries iniciais, é possível identificar, apesar da legislação dispor de algumas políticas educacionais no âmbito das TICs, como o ProInfo reflete uma realidade divergente da proposta.

Já com relação ao Programa de Inovação Educação Conectada, Catanante, Campos e Loiola (2020) salientam que a proposta de oferecer internet rápida às escolas públicas seria uma proposta anterior à pandemia. Dessa maneira, o programa que estava em fase de expansão, cuja meta era ampliar o atendimento aos alunos da Educação Básica e verificar a qualidade da conectividade nas escolas, permanece com suas ações estáticas.

É fato que esses entraves, como a desvalorização, a escassez, o descuido e a paralisação de ações relatados pelos autores sobre as políticas educacionais digitais, no atual contexto da pandemia da COVID-19, têm sido acentuados, principalmente no setor público. De acordo com Silva e Sousa (2020), esse estado de emergência global corroborou a urgência de investimento e de reorganização das estratégias e práticas educacionais para a consolidação dos direitos sociais, culturais e econômicos e para o encolhimento das diferenças educacionais historicamente acumuladas.

Sabe-se que atualmente as diferenças educacionais, ou seja, as desigualdades entre escolas públicas e privadas, urbanas e rurais já existentes tornaram-se ainda mais evidentes. Para Pereira e Barros (2020), a luta dos menos privilegiados por uma educação democrática ocasiona esgotamento e inexistência de expectativa com relação às suas vidas e ao futuro, tendo em vista a falta de retorno recorrente aos seus esforços por igualdade. Assim, para a redução desses contrastes educacionais, é imprescindível que o governo promova políticas públicas educacionais com potencial de abranger os distintos contextos, mas para Oliveira et al. (2020), muitos impedimentos básicos ainda precisam ser obsoletos para o exercício pleno da educação digital.

Sob a ótica da pandemia, as instituições escolares adotaram o ensino remoto e outras metodologias pelo emprego de engenharias tecnológicas com o objetivo de manter as aulas e o vínculo com seus alunos. Todavia, para Oliveira et al. (2020), antes de se pensar em ensino remoto, ensino híbrido ou até mesmo em educação a distância precisa haver a igualdade do conhecimento e do acesso às TICs, pois a Educação é um direito constitucional.

A utilização das TICs como possibilidade e desa- fio para apoiar o ensino do ano letivo revelou que esses conhecimentos na Educação brasileira em todos os níveis e modalidades de ensino está aquém do esperado. Zandonadi, Zandonadi e Pesce (2021) indicam em seus estudos que a incorporação das TDICs no cotidiano escolar só promoverá satisfação quando houverem políticas públicas que promovam a formação desse conhecimento nos cursos superiores de licenciatura. Segundo Araújo, Echalar e Oliveira (2020), se antes da pandemia o manuseio de tais ferramentas era extensivamente indicado pelas entidades internacionais e normas nacionais, no contexto atual elas se tornaram condição essencial para a concretização dos mecanismos de ensino e continuidade do calendário escolar.

No que tange a uma das modalidades do ensino, tal qual a Educação Escolar Indígena, Pereira (2020) emerge a necessidade de ampla inclusão de política pública tecnológica das TDICs nessa categoria de ensino, visando acompanhar o novo paradigma do campo educacional mundial pautado pela mediação tecnológica em todos os níveis e particularidades de ensino. Sobre isso Silva e Sousa (2020) ressaltam que a Educação é direito de todos e o Poder Público deve elaborar políticas públicas educacionais considerando os diferentes contextos, com ou sem emergência.

Outrossim, embora algumas das ações até aqui implementadas relacionadas com a inclusão digital não tenham sido suficientes, as políticas públicas educacionais propõem orientar a Educação nacional de modo que esta responda às dificuldades da população e de progresso da nação. Dias et al. (2020) observaram que as políticas públicas, leis, programas, projetos e ações colaboram para a efetivação do aproveitamento de tais tecnologias na Educação brasileira, assim como contribuem para o crescimento de práticas pedagógicas inovadoras.

Em síntese, observa-se que a maioria das políticas de inclusão digital existentes possui ações direcionadas ao contexto interno da escola, contudo, diante do cenário atual, faz-se necessária a implantação de uma legislação que favoreça a integração de ferramentas tecnológicas, seja na escola ou em domicílio de alunos e professores, de modo permanente. Nesse sentido, Mariano (2020) constata a emergência da criação de um plano de ações pós-pandemia, por meio do qual o Poder Executivo, a partir de programas, efetive de maneira eficiente a democratização da internet para discentes e capacite os docentes para que busquem maiores experiências e aperfeiçoamentos digitais. 
PERCEPÇÕES SOBRE AS POLÍTICAS PÚBLICAS DE INCLUSÃO DIGITAL NA EDUCAÇÃO BÁSICA DURANTE A PANDEMIA DA COVID-19: UMA ANÁLISE BIBLIOGRÁFICA

\section{CONSIDERAÇÕES FINAIS}

Neste trabalho foram expostos os resultados de uma análise bibliográfica realizada a partir de um conjunto de 14 artigos de periódicos, os quais retrataram o contexto nacional entre os anos de 2020 e 2021. Portanto, dentro desse âmbito, o resultado da questão e os objetivos foram alcançados, desvelando as percepções evidenciadas por autores sobre as políticas educacionais de inclusão digital no tocante a programas existentes e aos limites e possibilidades do uso das TICs no ensino remoto impostos pela pandemia da Covid-19.

Em suma, ao ser feito um balanço geral das investigações, verificou-se que as principais barreiras apontadas pelos autores estavam relacionadas com as escolas públicas da zona rural, incluindo comunidades indígenas. Ademais, os alunos, os pais e os professores esbarraram, principalmente, na carência de internet de boa qualidade e de acesso a recursos tecnológicos, além da insuficiência de formação dos docentes sobre o uso dessas ferramentas. Contudo, várias possibilidades acerca dessas tecnologias no ensino remoto foram reveladas, tais como: interação, comunicação, inclusão, socialização, debates e recursos digitais - exemplificados por AVAs, classes virtuais, redes sociais, dentre outros - que permitiram a continuidade dos estudos nesse momento pandêmico.

Assim, considerando a revelação dos limites e alternativas das tecnologias evidenciadas e potencializadas no contexto atual e as políticas públicas explanadas como o Proinfo e o Programa de Inovação Educação Conectada - os pensamentos, as ideias, as concepções detalhadas nesta pesquisa apontaram a precisão de ressignificar tais políticas educacionais vigentes de inclusão digital, tendo em vista que, além dessas ações serem voltadas predominantemente para o cenário interno da escola, o acesso à internet e aos recursos digitais ainda não ocorre de forma igualitária para a efetivação de uma educação inclusiva e universal.

A principal limitação do estudo está relacionada com o Programa de Inovação Educação Conectada por possuir poucas referências que mostrem ações concretas, tendo em vista que essa política, na atualidade, ainda está em fase de expansão. Apesar disso, corroborou-se que a análise bibliográfica foi expressiva na presente pesquisa porque oportunizou identificar consideráveis produções científicas da atualidade. Dessa forma, foi possível obter o embasamento necessário para apontar as fragilidades da Educação brasileira referentes às políticas educacionais de inclusão digital, que embora existam, não são permanentes, proporcionando assim subsídios a outras pesquisas, à comunidade científica e à ciência de forma geral.
Por fim, como trabalhos futuros, planeja-se realizar outras pesquisas voltadas para ações atuais do governo referentes à inclusão digital, tendo como intuito perceber, caso aconteçam, as mudanças, as vantagens e as contribuições para o processo de ensino e aprendizagem da Educação brasileira.

\section{REFERÊNCIAS}

ALVES, G. L.; MAMEDE, S. B. Quando uma pandemia expõe as limitações da escola e da educação ambiental formal. Revista Brasileira de Educação Ambiental (RevBEA), v. 15, n. 4, p. 175-189, 2020.

ARAúJO, C. H. d. S.; ECHALAR, A. D. L. F.; OLIVEIRA, N. C. d. Educação e tecnologias. Revista Plurais-Virtual, v. 10, n. 2, p. 136-153, 2020.

BEZERRA, N. P. X.; VELOSO, A. P.; RIBEIRO, E. Ressignificando a prática docente: experiências em tempos de pandemia. Práticas Educativas, Memórias e Oralidades-Rev. Pemo, v. 3, n. 2, p. 323917-323917, 2021.

BRASIL. Constituição (1988). Constituição da República Federativa do Brasil. Brasília: Senado Federal, 1988. Disponível em: <https: //www2.senado.leg.br/bdsf/bitstream/handle/id/ 518231/CF88_Livro_EC91_2016.pdf> Acesso em: 19 mar. 2021.

. Leis de Diretrizes e Bases da Educação Nacional, 9.394 de 20 de dezembro de 1996. Brasília: MEC, 1996. Disponível em: <http: //www.planalto.gov.br/ccivil_03/leis/19394.htm> Acesso em: 11 abr. 2021.

Ministério da Educação e do Desporto (MEC). Portaria $n^{\circ}$ 522, de 09 de abril de 1997. Criação do Programa Nacional de Informática na Educação - ProInfo. Brasília: Diário Oficial da União, 1997. Disponível em: <http://www.dominiopublico. gov.br/download/texto/me001167.pdf> Acesso em: 19 mar. 2021.

Decreto $\mathrm{n}^{\circ}$ 6.300, de 12 de dezembro de 2007. Dispõe sobre o Programa Nacional de Tecnologia Educacional - ProInfo. Brasília: Diário Oficial da União, 2007. Disponível em: <http://www.planalto.gov.br/ccivil_03/ _Ato2007-2010/2007/Decreto/D6300.htm> Acesso em: 19 mar. 2021.

Ministério da Educação. Programa Nacional de Formação Continuada em 
PERCEPÇÕES SOBRE AS POLÍTICAS PÚBLICAS DE INCLUSÃO DIGITAL NA EDUCAÇÃO BÁSICA DURANTE A PANDEMIA DA COVID-19: UMA ANÁLISE BIBLIOGRÁFICA

Tecnologia Educacional (ProInfo Integrado). 2007. Disponível em: <http://portal.mec.gov. br/pec-g/271-programas-e-acoes-1921564125/ seed-1182001145/13156-proinfo-integrado> Acesso em: 19 mar. 2021.

Lei n. 13.005 de 25 de junho de 2014. Aprova o Plano Nacional de Educação -PNE e dá outras providências. 2014. Disponível em: <http://www.planalto.gov.br/ccivil_03/ _Ato2011-2014/2014/Lei/L13005.htm> Acesso em: 09 mar. 2021.

Decreto n. 9.204 de 23 de novembro de 2017. Institui o Programa de Inovação Educação Conectada e dá outras providências. Brasília: Diário Oficial da União, 2017. Disponível em: <http://www.planalto.gov.br/ccivil_03/ _Ato2015-2018/2017/Decreto/D9204.htm>. Acesso em: 09 mar. 2021.

Ministério da educação. Programa de Inovação Educação Conectada, 2017. 2017. Disponível em: <http://educacaoconectada.mec.gov.br/ 35-o-programa/149-o-programa>. Acesso em: 19 mar. 2021.

Base Nacional Comum Curricular. Brasília: Ministério da Educação, 2018. Disponível em: $<$ http://basenacionalcomum.mec.gov.br/images/ BNCC_EI_EF_110518_versaofinal_site.pdf $>$. Acesso em: 19 mar. 2021.

Dispõe sobre a substituição das aulas presenciais por aulas em meios digitais, enquanto durar a situação de pandemia do novo coronavírus - Covid-19,. Brasília: Portaria $\mathrm{n}^{\circ}$ 544, de 16 de junho de 2020, 2020. Disponível em: <https://www.in.gov.br/en/web/dou/-/ portaria-n-544-de-16-de-junho-de-2020-261924872> Acesso em: 19 mar. 2021.

Castro Filho, J. A.; SILVA, M. A. d.; MAIA, D. L. Lições do projeto um computador por aluno: estudos e pesquisas no contexto da escola pública. 1 . ed. Fortaleza: EdUECE, 2015. 13 p.

CATANANTE, F.; CAMPOS, R. C. de; LOIOLA, I. Aulas on-line durante a pandemia: Condições de acesso asseguram a participação do aluno? Revista Científica Educ@ ção, v. 4, n. 8, p. 977-988, 2020.

COSTA, L. M. Programa nacional de tecnologia educacional (proinfo) expansão, democratização e inserção das tecnologias na rede pública.
Quanta-Comunicação e Cultura, v. 1, n. 1, p. 52-63, 2015.

DAMASCENO, H. L. C.; BONILLA, M. H. S.; PASSOS, M. S. C. Inclusão digital no proinfo integrado: perspectivas de uma política governamental. Inclusão Social, v. 5, n. 2, p. 32-42, 2012.

DIAS, V. d. S.; ARAÚJO, C. G. S.; ARAÚJO, K. P. R.; ZAN, F. R.; NOGUEIRA, C. R. D. Tecnologias da informação e comunicação (tics) e a inovação das políticas públicas educacionais. Brazilian Journal of Development, v. 6, n. 11, p. 90819-90837, 2020.

LIMA, T. C. S. d.; MIOTO, R. C. T. Procedimentos metodológicos na construção do conhecimento científico: a pesquisa bibliográfica. Revista Katálysis, SciELO Brasil, v. 10, n. 1, p. 37-45, 2007.

MARIANO, J. d. A.; SILVA, M. A. d. As dificuldades e a importância do professor e da tecnologia em tempos de pandemia. REVISTA ELETRÔNICA HUMANA RES, v. 1, n. 002, p. 1, 2020.

OLIVEIRA, D. N. d. S.; MELO, C. G. da S.; RIBEIRO, L. T. F.; ALMEIDA, J. P. G. de; BASÍlIO, E. F.; LIMA, C. R. F.; CASTRO, E. R. de; NETO, J.

A. G. Perspectivas docentes sobre o uso das tdic na educação básica em tempos de pandemia do covid-19. Research, Society and Development, v. 9, n. 12, p. e5191210775-e5191210775, 2020.

PEREIRA, C. L. Política pública de inclusão das tecnologias digitais de informação e comunicação no ensino e aprendizagem na educação escolar indígena brasileira nos tempos atuais. Research, Society and Development, v. 9, n. 12, p. e8591210393-e8591210393, 2020.

PEREIRA, M. D.; BARROS, E. A. d. A educação e a escola em tempos de corona vírus. Revista Scientia v. 9, n. 28, p. 1, 2020.

PRATA, C. L. Gestão democrática e tecnologias de informática na educação pública: o Proinfo no Espírito Santo. 2005. Dissertação (Mestrado em Educação)) - Universidade Federal do Rio Grande do Sul, Porto Alegre, 2005.

SANTOS, P. S. M. B. d. Guia prático da política educacional no Brasil: ações, planos, programas e impactos. 1. ed. São Paulo: Cengage Learning, 2012.

SILVA, D. d. S. V.; SOUSA, F. C. d. Direito à educação igualitária e (m) tempos de pandemia: desafios, possibilidades e perspectivas no brasil. Revista Jurídica Luso-Brasileira, v. 6, n. 4, p. 961-979, 2020. 
SILVA, R. E.; CASAGRANDE, M. A. Programa educação conectada: o uso de tecnologia para o cumprimento das metas de educação básica no plano nacional de educação. Cadernos UniFOA, v. 15, n. 43, p. 110-120, 2020.

\section{UNESCO. Organização Mundial das Nações}

Unidas para Educação, Ciência e cultura:

Estratégias de ensino a distância em resposta ao

fechamento das escolas devido à COVID-19. 2020.

Disponível em: <https://unesdoc.unesco.org/ark: 148223/pf0000373305_por?posInSet=2\&queryId= 77786f42-baae-433c-8a08-13456509ee56> Acesso em: 25 mar. 2021.

VALENTE, J. A.; ALMEIDA, M. E. B. de. Políticas de tecnologia na educação no brasil: visão histórica e lições aprendidas. Archivos Analíticos de Políticas Educativas= Education Policy Analysis Archives, College of Education University of South Florida, v. 28, n. 1, p. 94, 2020.

ZANDONADI, A. N.; ZANDONADI, J. C.; PESCE, L. Inclusão digital e empoderamento na formação de professores: estudo dos programas federais banda larga nas escolas, proinfo integrado, portal do professor e tv escola. Pesquisa e Debate em Educação, v. 11, n. 1, p. 1-e31849, 2021. 